\title{
SCIDiC
}

International Journal of Anatomy and Applied Physiology (IJAAP)

ISSN: 2572-7451

\section{Cadaveric Study on the Anterolateral Ligament of Knee: A Clinical Perspective}

Research Article

Jyothi $\mathrm{SR}^{1 *}$, Sachin $\mathrm{KS}^{1}$, Vasudha $\mathrm{TK}^{2}$, Vidyashambhava Pare $^{3}$

${ }^{1}$ Associate Professor, Department of Anatomy, K.V.G. Medical College and Hospital, Kurunjibagh, Sullia, Dakshina Kannada, India.

${ }^{2}$ Professor, Department of Anatomy, Subbaiah Institute of Medical Sciences, Purale, Shivamogga, India.

${ }^{3}$ Professor and Head, Department of Anatomy, K.V.G. Medical College and Hospital, Kurunjibagh, Sullia, Dakshina Kannada, India.

\section{Abstract}

Background: The original discovery of an extra-articular ligamentous structure on the anterolateral aspect of the knee, now called the "Anterolateral ligament (ALL)" is credited to Dr Paul Segond. The ALL plays a key role in maintaining the rotational stability of tibia, hence a deeper comprehension of morphology of the ALL is necessary.

Objective: To study the qualitative and quantitative characteristics of the ALL.

Materials and methods: The study was conducted on 44 embalmed human cadaveric knees (34 male and 10 female), mean age 78.1 years. The various dimensions of the ALL (length, width, thickness) were measured using Verniercaliper, and its relations with surrounding structures were noted.

Results: The mean length of the ALL in extension was $34.91 \pm 5.39 \mathrm{~mm}$ and $39.15 \pm 5.46 \mathrm{~mm}$ at $90^{\circ}$ flexion, indicating stretching of the ligament during mid-flexion. The mean width of the ALL at femoral origin measured $8.33 \pm 2.74 \mathrm{~mm}$, at joint line $9.50 \pm 3.06 \mathrm{~mm}$ and distal flaring at tibial insertion was clearly visible with mean width of $10.45 \pm 2.63 \mathrm{~mm}$. The ALL thickness at the joint line after separating it from lateral meniscus was $5.37 \pm 0.91 \mathrm{~mm}$. The lateral tibial recess was $7.32 \pm 1.72 \mathrm{~mm}$. The average distance between the centre of tibial ALL insertion to Gerdy's tubercle was $19.33 \pm 3.35 \mathrm{~mm}$ and to the tip of the fibular head was $21.03 \pm 5.78 \mathrm{~mm}$. There were no significant sex differences in any of the comparison.

Conclusion: This study clarifies the long-standing enigma surrounding the existence of a ligamentous structure, connecting femur with the anterolateral aspect of proximal tibia.

Keywords: ALL: Antero Lateral Ligament; ACL: Anterior Cruciate Ligament; GT: Gerdy's Tubercle; ITB: Ilio Tibial Band; LCL: Lateral Collateral Ligament.

\section{Introduction}

The lateral soft tissues of the knee are arranged in three layers, which collectively have been referred to as the lateral collateral ligamentous complex. The most superficial layer is the lateral patellar retinaculum. The anterolateral ligament of the knee may exist in the middle layer. The deeper layer is the lateral part of the capsule [1].

Dr. Paul Segond was the first to describe that forced internal rotation at the knee leads to a remarkable avulsion fracture at the anterolateral aspect of proximal tibia 'above and behind the tubercle of Gerdy'. In 1879, Segond described the structure at the anterolateral aspect of knee as "a pearly, resistant, fibrous band which invariably showed extreme amounts of tension during forced internal rotation of the knee" attached to the eponymous Segond fracture [2].

Over years different authors used various terms to describe this structure at the anterolateral aspect of knee such as "mid lateral capsular ligament", "lateral capsular ligament", "mid third lateral capsular ligament", "anterior oblique band" [3-8]. The credit for coining the term "Anterolateral ligament "(ALL) of knee is given to Vieira et al., [9].

Claes and colleagues published in their paper a distinct ligamentous structure at the anterolateral aspect of knee joint called 'An-

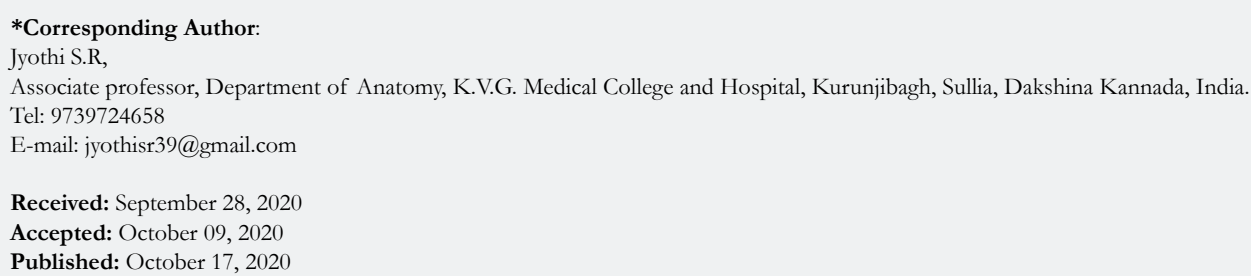

Copyright: Jyothi SR ${ }^{\circ}$ 2020. This is an open-access article distributed under the terms of the Creative Commons Attribution License, which permits unrestricted use, distribution and reproduction in any medium, provided the original author and source are credited. 
terolateral ligament'. They have not only given appropriate references to historical accomplishments but, delved more deeply into the origin, insertion and its relations to the surrounding structures[10]. This has triggered the interest regarding the importance, function and potential need to reconstruct the anterolateral ligament of the knee when injured.

The clinical importance of the ALL has been described after demonstrating in patients with possible combined anterior cruciate ligament(ACL) and ALL rupture, there was residual rotational laxity which is a positive 'pivot-shift' test following isolated ACL reconstruction [11]. The concurrent reconstruction of ACL and ALL results in significantly reduced internal rotation and axial plane tibial translation compared with isolated anterior cruciate ligament reconstruction [12].

The main goal of this study was to study the existence and detailed anatomical characteristics of the ALL, as it plays a key role in maintaining the rotational stability of tibia.

\section{Materials and Methods}

In this study 44 embalmed human cadaveric knees (34 male and 10 female), mean age of 78.1 years (range 61-94) were collected from the department of Anatomy, KVG Medical College and Hospital, Sullia. The specimens that had incision scars indicating a surgical history were excluded. The specimens with severe arthritis, osteophytes or degeneration that could cause difficulty with movements were excluded as well.

The dissection was performed according to the protocol established by Claes et al. [10]. Dissection was centred on the lateral aspect of the flexed knee and a large rectangular cutaneous flap was created. The iliotibial band (ITB) was defined and cut transversely at approximately $6 \mathrm{~cm}$ proximal to the lateral femoral epicondyle and then carefully released from its tibial attachment on Gerdy's tubercle. With ITB reflected, the superficial lamina of the capsule was visualised. The lateral collateral ligament (LCL) was palpated with the knee in slight varus. With knee flexed to 60 degree, distinct fibers running from lateral epicondyle to the proximal tibia posterior to Gerdy's tubercle was identified. The relation of the ALL with surrounding structures was noted by delineating the lateral meniscus, the lateral inferior genicular artery, and the LCL and popliteus tendon. Finally, a qualitative and quantitative characteristic of the ALL was studied. Each ALL was described with regard to origin, insertion, interconnecting fibers with LCL, lateral intermuscular septum and lateral meniscus. The following parameters of the ALL were measured using aVerniercaliper:

1. The ALL length in extension and at flexion $\left(90^{\circ}\right)$.

2. The ALL width at the femoral origin, joint line and at tibial insertion.

3. The ALL thickness at the joint line.

4. The depth of the tibial synovial recess (distance between the proximal tibial cartilage surface and the insertional fold of the ALL at the proximal tibia).

5. The distance between the centre of the ALL insertion to Gerdy's tubercle and to the tip of the fibular head.

\section{Statistical analysis}

Quantitative characteristics were described using mean and standard deviation. The paired-t-test and Pearson correlation was used to assess changes within the ALL length from extension to $90^{\circ}$ flexion, and the width at femoral origin and at its insertion on the anterolateral aspect of proximal tibia.

\section{Results}

The qualitative and quantitative characteristics of the ALL.

\section{Qualitative characteristics}

A distinct ligamentous structure was identified in 40 knees $(90.9 \%)$ out of 44 dissected specimens at the anterolateral side of the knee joint connecting femur with tibia. The origin was from the lateral femoral epicondyle, anterior to LCL, proximal and posterior to the insertion of the popliteus tendon. In majority of cases, the most superficial fibers of the ALL continued with lateral intermuscular septum of the thigh and posterior fibers of the proximal ALL merged with proximal part of the LCL. The ALL described an oblique course to the anterolateral side of the proximal tibia. The connecting fibers between the ALL and lateral meniscus was observedhence, the ALL was divided into meniscofemoral and meniscotibial portion above and under meniscal rim, respectively. At the level of joint line, the lateral inferior genicular artery (LIGA) and vein were found between the ALL and the lateral meniscus. The tibial insertion of the ALL was posterior to Gerdy's tubercle, with no connecting fibers to the ITB (Figure 1A).

Figure 1A. A photograph of lateral view of left knee showing the relations of the ALL. 1B. Anatomic drawing showing the relations of the ALL.

$1 \mathrm{~A}$

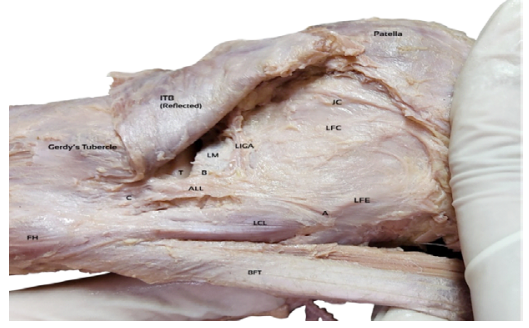

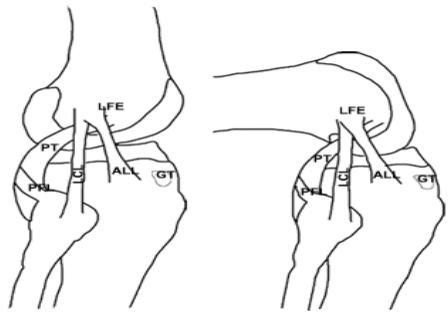

1B

ALL - Anterolateral ligament; AB - meniscofemoral portion and BC- meniscotibial portion, BFT- Biceps femoris Tendon, FH- Fibular head, GT- Gerdy's tubercle, ITB- Iliotibial band, JC-joint capsule, LCL- Lateral collateral ligament, LFC- Lateral femoral condyle, LFE - Lateral femoral epicondyle, LIGA- Lateral inferior genicular artery, LM- Lateral meniscus, PT - Popliteus tendon, T-Tibia. 
Graph 1. Correlation of length change pattern of the ALL from extension to flexion $\left(90^{\circ}\right)$.

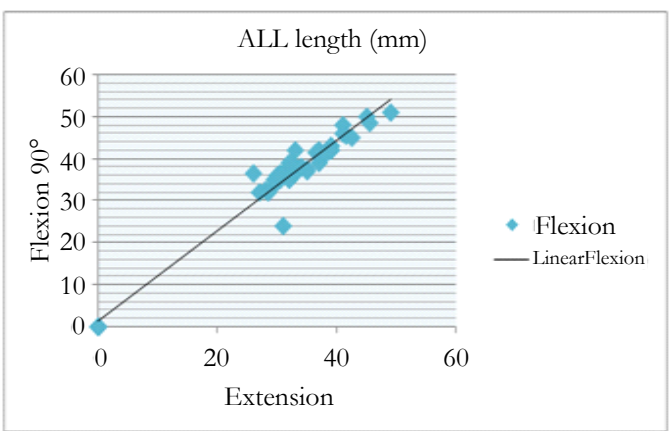

Graph 2. Correlation of width of the ALL at its femoral origin and at tibial insertion.

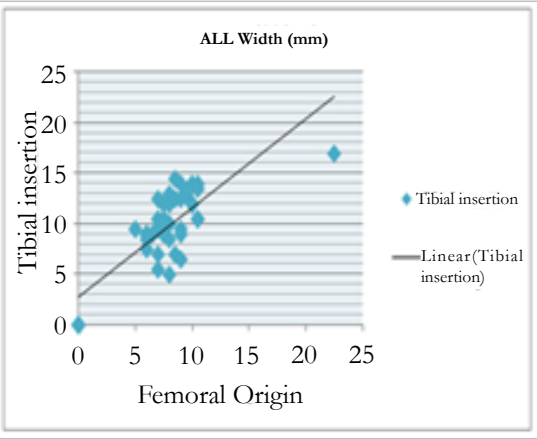

\section{Quantitative characteristics}

The mean length of the ALL in extension was $34.91 \pm 5.39 \mathrm{~mm}$, and $39.15 \pm 5.46 \mathrm{~mm}$ at $90^{\circ}$ flexion. This increase in length at flexion was highly significant $(\mathrm{p}<0.0001)$ (Graph1). The mean width of the ALL at femoral origin measured $8.33 \pm 2.74 \mathrm{~mm}$, at joint line $9.50 \pm 3.06 \mathrm{~mm}$ and distal flaring at tibial insertion was clearly visible with mean width of $10.45 \pm 2.63 \mathrm{~mm}$ which was highly significant $(\mathrm{p}<0.0001)$ (Graph 2). The ALL thickness at the joint line after separating it from lateral meniscus was $5.37 \pm 0.91 \mathrm{~mm}$. The lateral tibial recess was $7.32 \pm 1.72 \mathrm{~mm}$. The average distance between the centre of tibial ALL insertion to Gerdy's tubercle was $19.33 \pm 3.35 \mathrm{~mm}$ and to the tip of the fibular headwas 21.03 $\pm 5.78 \mathrm{~mm}$. The ALL insertion at the proximal tibia was grossly found in the middle of the line connecting the Gerdy's tubercle with the tip of fibular head.

The mean length of ALL, when knee extended was $34.90 \mathrm{~mm}$ in males and $34.95 \mathrm{~mm}$ in females. During flexion the mean length was $38.98 \mathrm{~mm}$ for males and $39.65 \mathrm{~mm}$ in females. The width of ALL at femoral origin and tibial insertion in males was $8.30 \mathrm{~mm}$ and $10.38 \mathrm{~mm}$ respectively and in females $8.45 \mathrm{~mm}$ and $10.65 \mathrm{~mm}$ respectively. There was no significant sex difference in any of the comparison.

\section{Discussion}

The most important observation of the present study is that, a distinct ligamentous structure, the ALL was identified at the anterolateral aspect of the human knee. The ALL has attracted many researchers attention, after the study by Claes et al., [10]. Nevertheless, a lot of controversy exists regarding the presence and morphometric characteristics of the ALL. Therefore, we conducted this morphometric study to analyze the ligamentous structure in the anterolaterlal region of the knee.

In the present study, 40 out of 44 dissected knees, the ALL was found to originateon the lateral femoral epicondyle, proximal and posterior to the popliteus tendon insertion (Figure 1B). In this view Claes et al., [10] and our observations are concurrent. However, our findings do not agree with the description of Vincent et al. [13], wherein they described in 9 out of 10 cases the origin of the ALL on the lateral femoral condyle, just anterior to the popliteus tendon insertion closely blending with its fibers.Dodds et al. [14] described the origin of the ALL, just posterior and slightly proximal to the lateral collateral ligament. In our study, the ALL was closely related to the anterior fibers of the proximal part of the lateral collateral ligament.Claes et al. [10] proposed the term 'lateral collateral ligament complex' to include both the ALL and LCL, since their femoral origin was so closely associated. They considered the ALL as the lateral counterpart of the deep medial collateral ligament.

The ALL was clearly distinguishable from the capsulo-osseous layer of ITB (Figure 2). This observation is consistent with the previous reports wherein, the 'capsulo-osseous layer of the ITB' has been described as originating from the investing fascia of the lateral head of gastrocnemius without any bony origin, coursing obliquely similar to the ALL and has tibial attachment in close relation to the ALL. The third layer of the ITB, 'capsulo-osseous layer', which is seen after retracting the superficial and deep layers (Kaplan's fibers), should not be confused with the ALL. However to understand the real significance of the ALL and the capsuloosseous layer, further biomechanical and clinical research are necessary $[10,15-17]$.

In the current study, a strong connection between the ALL and the periphery of the middle third of the lateral meniscus was ob- 
Figure 2. A Photograph of lateral view of left knee showing, that the ALL is visible after detaching the superficial, deep fibers and the capsulo - osseous layer (COL) of the ITB.

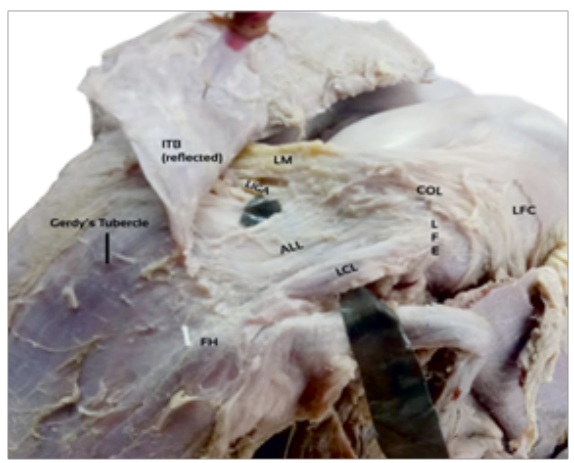

Legends:

ALL - Anterolateral ligament, COL- Capsulo-osseous layer, FH- Fibular head, GT - Gerdy's tubercle, ITB- Iliotibial band, LCL- Lateral collateral ligament, LFC- Lateral femoral condyle, LFE - Lateral femoral epicondyle, LIGA- Lateral inferior genicular artery, LM-

Lateral meniscus.

Table 1. Comparison of the mean length and width of the ALL with the previous reports.

\begin{tabular}{|c|c|c|c|c|c|c|}
\hline \multirow[t]{2}{*}{ Authors } & \multirow{2}{*}{$\begin{array}{l}\text { Number of speci- } \\
\text { mens and inci- } \\
\text { dence of ALL }\end{array}$} & \multicolumn{2}{|c|}{ ALL length (mm) } & \multicolumn{3}{|c|}{ ALL width (mm) } \\
\hline & & Extension & $\begin{array}{c}\text { Flexion } \\
\left(90^{\circ}\right)\end{array}$ & $\begin{array}{c}\text { Femoral } \\
\text { origin }\end{array}$ & $\begin{array}{l}\text { Joint } \\
\text { line }\end{array}$ & Tibial insertion \\
\hline Claes et al. [10] & 41 cadavers, $97 \%$ & $38.5 \pm 6.1$ & $41.5 \pm 6.7$ & $8.3 \pm 2.1$ & $6.7 \pm 3.0$ & $11.2 \pm 2.5$ \\
\hline Helito et al. [11] & 20 cadavers, $100 \%$ & \multicolumn{2}{|c|}{$37.3 \pm 4.0$} & \multicolumn{3}{|c|}{$7.4 \pm 1.7$} \\
\hline Vincent et al [13] & 10 cadavers, $100 \%$ & $34.1 \pm 3.4$ & $8.2 \pm 1.5$ & $6.98 \pm 0.95$ & - & $9.36 \pm 1.07$ \\
\hline Stijak et al. [18] & 14 cadavers, $50 \%$ & \multicolumn{2}{|c|}{$41 \pm 3$} & \multicolumn{3}{|c|}{$4 \pm 1.0$} \\
\hline Present study & 44 cadavers, $90.9 \%$ & $34.91 \pm 5.39$ & $39.15 \pm 5.46$ & $8.33 \pm 2.74$ & $9.50 \pm 3.06$ & $10.45 \pm 2.63$ \\
\hline
\end{tabular}

Table 2. Comparison of the mean distance, between the tibial ALL insertion to the Gerdy's tubercle and to the tip of fibular head.

\begin{tabular}{|c|c|c|}
\hline Authors & $\begin{array}{c}\text { Tibial ALL insertion to the } \\
\text { Gerdy's tubercle }\end{array}$ & $\begin{array}{c}\text { Tibial ALL insertion to the } \\
\text { tip of fibular head }\end{array}$ \\
\hline Claes et al. [10] & $21.6 \pm 4.0 \mathrm{~mm}$ & $23.2 \pm 5.7 \mathrm{~mm}$ \\
\hline Dodds et al. [14] & $18 \pm 3 \mathrm{~mm}$ & $17 \pm 3 \mathrm{~mm}$ \\
\hline Present study & $19.33 \pm 3.35 \mathrm{~mm}$ & $21.03 \pm 5.78 \mathrm{~mm}$ \\
\hline
\end{tabular}

served. Hence, the ALL was divided into meniscofemoral and meniscotibial portion (Figure 1A). This observation is concurrent with the studies by Claes et al.[10], Helito et al. [11], and Vincent et al. [13]. But not in line with Dodds et al. [14], wherein they explained, the ALL and the lateral meniscus had no connecting fibres. However, in association with ALL, additional fibres starting at the lateral femoral epicondyle and running circumferentially around the rim of lateral meniscus and getting inserted there was noted by some authors [11-17].

The ALL was described as a local thickening of parallel bundles of collagen fibers in the fibrous capsule at the anterolateral region of the knee, and was defined as a capsular ligament of the knee, named after the attachment site as the 'anterolateral (capsular) ligament [16]. We also agree on this view, as the fibers of the anterior border of the ALL had merged with the joint capsule (Figure1A). The quantitative characteristics of the ALL, compared with studies of various authors (Table 1,2). The differences in parameters could be due to varied population groups among the studies. We observed the insertion of the ALL was approximately in the mid- dle of the line joining the Gerdy's tubercle with the tip of fibular head. This finding is concurrent with Claes et al. [10], Dodds et al. [14]. This surface anatomical landmark may aid during the ALL reconstruction.

The ALL plays a major role in controlling internal tibial rotation at knee flexion angles greater than $35^{\circ}$ [19]. We also observed the ALL getting taut between $30^{\circ}-90^{\circ}$ of knee flexion and forced internal rotation.Monaco et al. [20] demonstrated in their biomechanical work that the soft tissue structures in the anterolateral part of the knee are crucial for controlling internal rotation, whereas the ACL plays a minor role.

Rasmussen et al. [21], found that combined ACL and ALL reconstruction give a better surgical outcome, compared to isolated ACL reconstruction in knee injuries. Sonnery-Cottet et al. [22], found increased stability at 2-year follow up in patients who underwent concurrent ACL and ALL reconstruction. The study compared preoperative versus postoperative pivot shift to define stability. The number of grade one pivot shifts went from 41 
to 7 and the number of negative pivot shifts rose from 0 to 76 $(\mathrm{p}<0.0001)$.

The bony avulsion of the ALL is often pathognomonic of ACL injuries. This explains the importance of ALL in rotator knee instability patterns encountered in ACL deficient knees (i.e., pivot shift phenomenon) [10]. Further studies are needed to understand the function of the ALL and to decide its role in clinical knee injuries.Added to the anatomical study, the advanced radiological, biomechanical and clinical knowledge could broaden the treatment modalities in patients with the anterior cruciate ligament tear.

\section{Conclusion}

The information on the precise anatomy and function of this entity has always been vague and confusing; hence, the present study was conducted. The study confirms the existence of a distinct ligamentous structure, the ALL with consistent origin and insertion sites. It could be hypothesized to play a major role in maintaining the anterolateral stability of knee. The morphometric characteristics of the ALL of the present study may be of value during anatomic reconstruction of the ALL. This is an attempt to reassess the lateral soft tissue of the knee to elucidate the morphology of the ALL.

\section{References}

[1]. Standring S, Anand N, Birch R, Collins P, Crossman AR. Gray's anatomy: Knee. (41stedtn). Elsevier. London. 2016.

[2]. Campos JC, Chung CB, Lektrakul N, R Pedowitz, D Trudell, J Yu, et al. Pathogenesis of Segond fracture: anatomic and MR imaging evidence of an iliotibial tract or anterior oblique band avulsion. Radiology. 2001; 219: 381386. PMID:11323461.

[3]. Davis DS, Post WR. Segond fracture: lateral capsular ligament avulsion. J Orthop Sports Phys. 25: 103-6. PMID: 9007767.

[4]. Goldman AB, Pavlov H, Rubenstein D. The segond fracture of the proximal tibia: a small avulsion that reflects major ligamentous damage. AJR Am J Roentgenol. 1988; 151: 1163-7. PMID: 3263770.

[5]. Johnson LL. Lateral capsular ligament complex: anatomical and surgical considerations. Am Sports Med. 1979; 7: 156-160. PMID: 464170.

[6]. Hughston JC, Andrews JR, Cross MJ, Moschi A. Classification of knee ligament instabilities Part 2.The lateral compartment. J Bone Joint Surg Am. 1976; 58: 173-9. PMID: 1254620.

[7]. Lobenhoffer P, Posel P, Witt S, Piehler J, Wirth CJ. Distal femoral fixation of the iliotibial tract. Arch Orthop Trauma Surg. 1987; 106: 285-90. PMID: 3632313.

[8]. Irvine GB, Dias JJ, Finlay DB. Segond fractures of the lateral tibial condyle: brief report. J Bone Joint Surg Br. 1987; 69: 613-4. PMID: 3611168

[9]. Vieira EL, Vieira EA, da Silva RT, BerifeinPA, Abdalla RJ, Cohen M. An anatomical study of the iliotibial tract. Arthroscopy. 2007; 23: 269-274.

[10]. Claes S, Vereecke E, Maes M, Victor J, Verdonk P, Bellemans J. Anatomy of the anterolateral ligament of the knee. J Anat. 2013; 223: 321-8. PMID: 23906341.

[11]. Helito CP, Bonadio MB, Rozas JS, Wey JM, Pereira CA, Cardoso TP, et al. Biomechanical study of strength and stiffness of the knee anterolateral ligament. BMC Musculoskeletal Disord. 2016; 17: 193. PMID: 27129387.

[12]. Kraeutler MJ, K Linnea Welton, Jorge Chahla, Robert F LaPrade, Eric C McCarty. Currents concepts of the anterolateral ligament of the knee: Anatomy, biomechanics and reconstruction. Am J Sports Med. 2018; 46(5): 1235-1242. PMID: 28426251.

[13]. Vincent JP, Magnussen RA, Gezmez F, Uguen A, Jacobi M, Florent Weppe, et al. The anterolateral ligament of the human knee: an anatomic and histologic study. Knee Surg Sports TraumatolArthrosc. 2012; 20: 147-152. PMID: 21717216.

[14]. Dodds AL, Halewood C, Gupta CM, Williams A, Amis AA. The anterolateral ligament: Anatomy, length changes and association with the Segond fracture. Bone Joint J. 2014; 96-B (3): 325-331. PMID: 24589786.

[15]. TerryGC, Hughston JC, Norwood LA. The anatomy of the iliopatellar band and iliotibial tract. Am J Sports Med. 1986; 14: 39-45. PMID: 3752345.

[16]. Cho HJ, Kwak DS. Anatomical Consideration of the Anterolateral Ligament of the Knee. BioMed Research International. 2019; 2019: 1-6.

[17]. Runer A, Birkmaier S, Pamminger M, Reider S, Herbst E, Karl-Heinz Künzel, et al. The anterolateral ligament of the knee: A dissection study. The Knee. 2016; 23: 8-12. PMID: 26749203.

[18]. Stijak L, Bumbasirevic M, Radonjic V, Kadija M, Puskas L, Darko Milovanović, et al. Anatomic description of the anterolateral ligament of the knee. Knee Surg Sports Traumatic Arthrosc. 2016; 24(7): 2083-8. PMID: 25380973.

[19]. Parson EM, Gee AO, Spiekeman C, Cavanagh PR. The biomechanical function of the anterolateral ligament of the knee. Am J Sports Med. 2015; 43: 669-74. PMID: 25556221

[20]. Monaco E, Maestri B, Labianca I, Speranza A, Kelly MJ, Carmelo D'Arrigo, et al. Navigated knee kinematics after tear of the ACL and its secondary restraints: preliminary results. Orthopaedics. 2010; 33: 87-93. PMID: 20954638.

[21]. Rasmussen MT, Nitri M, Williams BT, Moulton SG, Cruz RS, Grant J Dornan, et al. An invitro robotic assessment of the anterolateral ligament , part2: Anterolateral ligament reconstruction combined with anterior cruciate ligament reconstruction. Am J Sports Med. 2016; 44(3): 593-601. PMID: 26831632.

[22]. Sonnery-Cottet B, Thaunat M, Freychet B, Pupim BH, Murphy CG, Steven Claes. Outcome of a combined anterior cruciate ligament and anterolateral ligament reconstruction technique with a minimum 2-year follow up. Am J Sports Med. 2015; 43: 1598-1605. PMID: 25740835. 